JURNAL ABDI INSANI UNIVERSITAS MATARAM

Volume 8, Nomor 1, April 2021

Homepage : http://abdiinsani.unram.ac.id. e-ISSN : 2657-0629

\title{
WEBINAR PENGENALAN GOOGLE CLASSROOM DAN GOOGLE FORM SEBAGAI MEDIA DAN ALAT EVALUASI PEMBELAJARAN DARING PADA MASA PANDEMI COVID-19
}

\section{Google Classroom and Form Introduction as a Media and Evaluation Tool for Online Learning in the Covid-19 Pandemic}

\author{
Ni Wayan Switrayni ${ }^{*}$, I Gede Adhitya Wisnu Wardhana, Irwansyah, Qurratul Aini, Salwa \\ 1)Program Studi Matematika Universitas Mataram \\ Jalan Majapahit Nomor 62 Kota Mataram
}

*Alamat korespondensi: niwayan.switrayni@unram.ac.id

(Tanggal Submission: 30 November 2020, Tanggal Accepted : 28 April 2021)

\begin{abstract}
Keyword: Abstract :
Webinar, Kegiatan pembelajaran di setiap jenjang pendidikan termasuk di sekolah dasar selama Media masa pandemi Covid-19 ini tidak dapat dilaksanakan melalui tatap muka langsung. Pembelajar Akibatnya, guru dituntut untuk dapat mengelola pembelajaran secara daring. an Daring, Google Classroom, Google Form, Sekolah Dasar Sebagian besar guru memanfaatkan media yang paling sederhana yakni dengan menggunakan media WhatsApp. Akan tetapi, media ini memiliki keterbatasan dalam hal layanan yang dapat digunakan guru dalam mengelola kelas. Kegiatan Pengabdian Kepada Masyarakat ini bertujuan untuk memberikan pengenalan terhadap para guru sekolah dasar khususnya di Kota Mataram berupa alternatif media pembelajaran daring yaitu Google Classroom dan alat evaluasinya menggunakan Google Form. Kegiatan pengabdian kepada masyarakat ini dilaksanakan melalaui webinar menggunakan flatform aplikasi zoom meeting. Hasil kegiatan ini adalah para guru SD se-Kota Mataram diberikan tutorial menggunakan media pembelajaran digital yang bisa digunakan dalam proses pembelajaran daring selama masa pandemic covid-19, yakni Google Classroom dan Google Form. Diskusi untuk para peserta dengan pemateri juga diadakan dan para guru antusias bertanya selama sesi ini. Berdasarkan pengamatan selama pelaksanaan kegiatan pengabdian kepada masyarakat ini, dapat disimpulkan bahwa webinar telah dilaksanakan dengan cukup baik dan lancar, serta para guru sudah mampu membuat media pembelajaran daring seperti yang sudah diberikan.
\end{abstract}

Panduan sitasi / Citation guidance (APPA $7^{\text {th }}$ edition) :

Switrayni, N.W., Wardhana, I.G.A.W., Irwansyah, Aini, Q., \& Salwa. (2021). Webinar Pengenalan Google Classroom Dan Google Form Sebagai Media Dan Alat Evaluasi Pembelajaran Daring Pada Masa Pandemi Covid-19. Jurnal Abdi Insani Universitas Mataram, 8 (1), 18-24. http://doi.org/10.29303/abdiinsani.v8i1.366. 


\section{PENDAHULUAN}

Pandemi Covid-19 telah melanda hampir di seluruh negara di dunia termasuk Indonesia. Dengan tingkat penularan yang sangat cepat dan resiko yang sangat serius yang dapat ditimbulkannya, semua negara terdampak memiliki cara masing-masing dalam rangka pemutusan mata rantai penularannya. Tidak hanya pada bidang ekonomi, tetapi hampir pada seluruh aspek kehidupan ikut terdampak oleh wabah penyakit ini termasuk dalam aspek pendidikan.

Pada dunia pendidikan khususnya, selama masa pandemi covid-19, pembelajaran di setiap jenjang pendidikan termasuk di sekolah dasar tidak dapat dilaksanakan melalui tatap muka langsung. Hal ini tentunya untuk menghindari kontak langsung antar individu dan agar tidak menciptakan kerumunan yang dapat memicu adanya transmisi lokal. Akibatnya, semua kegiatan pembelajaran secara offline di sekolah ditiadakan dan diganti dengan sistem online (daring). Hal ini membuat guru dituntut untuk dapat mengelola pembelajaran secara daring. Pembelajaran secara daring ini lebih dikenal dengan istilah elearning. E-learning adalah pembelajaran yang disusun dengan tujuan menggunakan sistem elektronik atau komputer sehingga mampu mendukung proses pembelajaran (Michael, 2013:27).

Dalam rangka melaksanakan kegiatan pembelajaran yang berbasis elektronik ini, sebagian besar guru memanfaatkan media sosial yang paling sederhana dan familiar digunakan sehari-hari yakni dengan menggunakan media WhatsApp. Akan tetapi media ini memiliki keterbatasan diantaranya yakni terkait pengelolaan materi ajar, jadwal mata pelajaran, dan pengorganisasian tugas atau ujian khususnya dalam mengajar mata pelajaran matematika. Matematika adalah disiplin ilmu yang tidak hanya terkait dengan masalah di kehidupan nyata saja, tetapi juga ilmu yang melibatkan intuisi, imajinasi dan penalaran untuk mendapatkan ide-ide baru dan menyelesaikan masalah-masalah rumit. Matematika adalah suatu studi yang melibatkan suatu sistem deduksi yang abstrak yang melibatkan suatu himpunan dari objek-objek yang tak terdefinisi secara sederhana, definisi yang berkembang dari objek-objek yang tak terdifinisi, aksioma atau postulate, serta teorema dan buktinya (Khan, 2015).

Berdasarkan pandangan tersebut, matematika khususnya dalam pembelajarannya sering kali mengkaji objek -objek yang bersifat abstrak. Dengan sifat yang abstrak ini diperlukan suatu metode dan media pembelajaran yang dapat menjembatani sifat yang abstrak tersebut dengan aspek kognitif siswa SD yang masih berada pada tahap penalaran konkrit. Khususnya pada masa pandemic Covid-19 ini, pada guru dituntut untuk tetap dapat melayani siswa melalui pembelajaran daring dan tentunya dengan tetap berusaha semaksimal mungkin untuk menciptakan pembelajaran yang menyenangkan bagi siswa. Hal ini dikarenakan bahwa menjadi senang adalah hal yang sangat produktif yang dapat dilakukan untuk bisa maju (Sepalla, 2016).

Oleh karena itu, untuk mengatasi masalah tersebut, kegiatan Pengabdian Kepada Masyarakat ini bertujuan untuk memberikan pengenalan terhadap para guru SD khususnya di Kota Mataram berupa alternatif media pembelajaran daring yaitu Google Classroom dan alat evaluasinya menggunakan Google Form. Adapun kegiatan pengabdian ini akan diselenggarakan dalam bentuk webinar. Melalui kegiatan ini diharapkan keterampilan guru SD se-Kota Mataram dalam menyiapkan media pembelajaran secara daring dapat meningkat. 


\section{METODE KEGIATAN}

Kegiatan Pengabdian Kepada Masyarakat ini dilaksanakan oleh kelompok bidang ilmu Aljabar program studi Matematika FMIPA Universitas Mataram dengan mengadakan webinar pengenalan media pembelajaran daring berupa Google Classroom dan alat evaluasinya menggunakan Google Form terhadap para guru SD khususnya di Kota Mataram. Kegiatan ini meliputi 3 tahap yakni:

1) Tahap awal adalah menyiapkan materi webinar dan menyiapkan perlengkapan yang dibutuhkan pada saat webinar seperti famplet dan spanduk elektronik.

2) Tahap kedua adalah sosialisasi pendaftaran webinar melalui media social WhatsApp. Proses pendaftaran peserta dilakukan melalui link Google Form yang telah dibuat.

3) Tahap ketiga adalah pelaksanaan kegiatan Pengabdian Kepada Masyarakat. Kegiatan Pengabdian Kepada Masyarakat ini dilaksanakan melalui aplikasi Zoom pada bulan Agustus 2020.Pada tahapan ini, dilakukan beberapa hal berikut.

a. Memberikan tutorial media pembelajaran menggunakan Google Classroom dan alat evaluasi berupa Google Form.

b. Diskusi dan tanya jawab dengan peserta webinar.

\section{HASIL DAN PEMBAHASAN}

Webinar Pengenalan Google Classroom dan Google Form sebagai Media dan Alat Evaluasi Pembelajaran Daring pada Masa Pandemi Covid-19 dilaksanakan pada tanggal 27 Oktober 2020. Peserta webinar sebanyak 56 orang, yang terdiri dari guru-guru SD, SMP dan SMA di NTB.

Pada kegiatan Pengabdian Kepada Masyarakat ini, tim pengabdian melibatkan dua orang mahasiswa dalam hal persiapan webinar seperti membuat famplet, spanduk, registrasi peserta, dan MC. Peserta melakukan registrasi dengan mengisi Google Form. Setelah melakukan registrasi, para peserta bergabung dalam suatu grup WhatsApp untuk mempermudah panitia dalam memberikan informasi terkait pelaksanaan webinar seperti tata tertib webinar dan link Zoom dan Youtube. Kegiatan webinar dapat disaksikan secara live melalui akun YouTube Gamatika Unram. Pada tanggal 27 Oktober 2020, pelaksanaan webinar dimulai pada pukul 09.00 Wita dengan diawali oleh sambutan dari Ketua Program Studi Matematika Universitas Mataram, Dr. Marwan, M.Si.

Setelah itu dilanjutkan dengan acara inti yaitu dengan pemateri pertama adalah $\mathrm{Ni}$ Wayan Switrayni, S.Pd.,M.Si. tentang “Media Pembelajaran Daring Matematika SD". Pada bagian ini dipaparkan secara singkat beberapa media pembelajaran daring yang bisa dimanfaatkan guru SD seperti Google Classroom, Google Form, Zoom, Google Meet,YouTube, maupun WhatsApp. Para guru diberikan pilihan untuk menggunakan beberapa diantara media tersebut disesuaikan dengan kondisi dan tujuan yang ingin dicapai.

Selanjutnya materi yang kedua oleh Dr. Adhitya Wisnu Wardana, M.Si dengan dimoderatori oleh Qurratul Aini, S.Si., M.Sc., yaitu cara menggunakan Google Classroom untuk guru. Berikut langkahlangkah menggunakan google classroom untuk para guru:

a. Membuat Kelas

Tahap ini adalah tahap awal untuk menggunakan classroom. Akan tetapi perlu diingat bahwa, untuk dapat membuat kelas, guru harus memiliki akun email google terlebih dahulu. Langkahlangkah dalam membuat kelas adalah sebagai berikut. 
1. Login dengan akun gmail

2. Buka situs https://classroom.google.com

3. Pilih 'Tambahkan' (simbol +)

4. Buat Kelas/Create Class

5. Tuliskan Nama Kelas yang akan dibuat

6. Isi keterangan pada pilihan Section (Bagian), Subject (Mata pelajaran), Room (Ruangan)

7. Jika sudah, maka klik 'Buat/Create'. Berikutnya kode kelas akan diperoleh.

b. Mengundang siswa ke kelas

Untuk mengundang siswa ke kelas yang sudah dibuat, dapat dilakukan dengan dua cara, yaitu melalui email siswa atau dengan membagikan kode kelas yang telah diperoleh pada tahap sebelumnya.

Berikut cara mengundang siswa melalui email:

1. Buka akun Google Classroom

2. Klik 'anggota', kemudian klik 'Undang siswa'

3. Masukkan alamat email siswa

4. Klik 'Undang'

Cara mengundang siswa menggunakan kode kelas yaitu guru cukup membagikan kode kelas kepada siswa dan memintanya bergabung dengan kode tersebut yaitu dengan cara sebagai berikut.

1. Siswa melakukan login ke https://classroom.google.com .

2. Kemudian klik Tambahkan (simbol +) di bagian pojok kanan atas, dan pilih 'Gabung kelas/join class'.

3. Masukkan kode yang telah dibagikan oleh guru, kemudian klik 'Gabung'.

c. Membuat Materi/Tugas untuk siswa

Untuk menyisipkan materi/tugas untuk siswa dapat dilakukan dengan langkah-langkah berikut ini.

1. Pilih 'Tugas Kelas'

2. Klik 'Buat' (tanda + )

3. Pilih 'materi' atau 'tugas'

4. Kemudian isi kolom judul, deskripsi (opsional),

5. Isi kolom topik untuk mempermudah pengaturan materi atau tugas

6. Jika butuh melampirkan file klik 'tambahkan' di bawah kolom deskripsi. Pada bagian ini dapat dipilih sumber materi atau tugas, yaitu dapat disisipkan dari Google Drive, YouTube, atau dapat ditambahkan berupa link . Jika file diambilkan dari computer, maka pilih file, pilih upload, kemudian browse dan klik file yang akan disisipkan.

7. Jika materi belum dibuat, dapat menggunakan opsi 'buat' di bawah kolom deskripsi, dan guru dapat memulai membuat materi atau tugas secara langsung.

8. Untuk tugas, guru dapat mengatur deadline tugas sesuai yang diinginkan, sehingga apabila ada siswa yang mengupload tugas melebihi tanggal dan waktu yang ditentukan, maka akan muncul status 'diserahkan terlambat'.

9. Guru juga bisa menambahkan rubrik dengan mengklik 'Rubrik' 
10. Langkah terakhir klik 'Tugaskan' untuk memposting tugas, atau klik jadwalkan jika ingin menjadwalkan, atau jika belum ingin diposting dapat pilih 'simpan draf', sedangkan untuk menghapus pilih 'hapus draf'.

Pada kegiatan pengabdian sebelumnya, para guru diberikan tutorial membuat media pembelajaran matematika menggunakan power point dimana media tersebut dapat digunakan guru menyampaikan materi dalam bentuk permainan yang menyenangkan bagi siswa yaitu membuat media pembelajaran interaktif menggunakan power point (Salwa, dkk., 2020). Para guru diberikan contoh untuk menyisipkan materi itu pada Google Classroom yang telah dibuat.

Selain menggunakan classroom, diberikan pula cara menggunakan google form sebagai alat evaluasi daring. Langkah-langkahnya sebagai berikut.

1. Buka situs https://www.google.com/intl/id/forms/about/

2. Pilih Google Formulir yang ingin digunakan yaitu 'Pribadi atau Bisnis'. Layanan 'Bisnis' sifatnya berbayar. Jadi untuk yang gratis, maka dapat dipilih yang 'Pribadi'.

3. Klik tanda ' + ' untuk memulai formulir baru dari awal.

4. Ganti isian 'Formulir tanpa judul' dengan judul ulangan/ujian yang akan dibuat.

5. Pada bagian 'deskripsi formulir', dapat diketik petunjuk soal.

6. Untuk membuat soal, klik tanda ' + ' di sisi bagian kanan, kemudian pilih tipe soal sesuai yang diinginkan, misalkan pilihan ganda.

7. Tuliskan pertanyaan dan opsi jawaban jika memilih tipe pilihan ganda.

8. Untuk menambah bagian, klik 'tambahkan bagian' pada sisi bagian kanan paling bawah. Dalam hal membuat formulir ujian, mungkin bagian pertama bisa digunakan untuk identitas siswa yang wajib diisi. Caranya sama seperti pada langkah 4-7, tetapi mengkin tipe pertanyaan dapat disesuaikan, dan untuk menentukan pertanyaan yang wajib dijawab siswa dapat dilakukan dengan mengaktifkan tombol 'wajib diisi' pada pertanyaan yang bersangkutan.

9. Untuk menambahkan gambar atau video juga dapat dipilih pada bagian sisi kanan tersebut.

10. Setelah semua soal selesai dimasukkan, saatnya mengatur konfigurasi agar siswa bisa menggunakan soal dari Google Form ini. Klik setting yang terletak di pojok kanan atas.

11. Akan muncul Pop-up halaman setting yang terdiri dari tiga kolom, yakni Umum, Presentasi, dan Kuis. Pertama-tama, atur bagian 'Umum'. Pilih 'kumpulkan alamat email' dan pada bagian 'Tanda terima jawaban' pilih 'selalu'. Pada bagian 'perlu masuk' pilih 'batasi ke 1 jawaban' agar siswa hanya bisa mengisi form 1 kali saja dengan akun yang sama.

12. Lalu, pindah ke bagian tab Kuis untuk mengaktifkan tombol-tombol seperti 'Jadikan ini sebagai kuis', 'Rilis nilai' dan 'Responden dapat melihat'. Pilihan-pilihannya disesuaikan saja.

13. Klik 'simpan'.

Berikutnya adalah membuat kunci jawaban, langkah-langkahnya adalah sebagai berikut.

1. Pastikan soal sudah dibuat di dalam Google Form sesuai langkah-langkah sebelumnya.

2. Pilih tombol "Kunci jawaban" yang ada di pojok kiri bawah form soal.

3. Pilih jawaban yang tepat untuk soal tersebut, kemudian berikan besaran poin untuk setiap jawaban yang benar.

4. Klik 'Selesai' jika sudah selesai mengisi kunci jawaban dan poin penilaian. 
5. Ulangi langkah 1 sampai 4 untuk soal-soal yang lain.

Untuk mengatur batas waktu pengerjaan ujian dapat dilakukan dengan langkah-langkah berikut.

1. Klik tanda titik tiga di sebelah kanan menu kirim, kemudian pilih 'add-on',

2. Pilih 'FormLimiter' kemudian install. Kemudian klik 'lanjutkan', dan login dengan akun email yang digunakan untuk membuat Google form tersebut. Kemudian pilih 'izinkan' lalu 'selesai'.

3. Setelah ini akan muncul kotak dialog formLimiter, kemudian pastikan form ujian yang sudah dibuat dalam kondisi aktif dengan menutup kotak dialog yang lain.

4. Selanjutnya isi kotak dialog 'formlimiter' dengan memilih 'Limit type' yaitu 'date and time' dan atur tanggal dan waktu berakhir ujian, kemudian klik 'set'.

5. Pada bagian kolom isian pesan, guru dapat mengisi pesan ketika ujian sudah ditutup.

6. Terakhir klik 'save and enable'.

Setelah seluruh tahapan pembuatan soal, kunci jawaban, dan pengaturan waktu ujian selesai, berikutnya adalah membagikan soal di dalam Google Form tersebut kepada siswa/siswi, yaitu dengan cara:

1. Klik tombol 'kirim' pada bagian pojok kanan atas

2. Klik tombol link, dan salin link yang muncul, kemudian kirim ke siswa/siswi.

3. Selesai.

Setelah semua materi disampaikan, sesi berikutnya adalah sesi tanya jawab untuk para peserta dengan pemateri. Para guru antusias bertanya selama sesi ini. Setelah semua pertanyaan terjawab, sesi ini diakhiri dengan pemberian link absensi pada para peserta webinar untuk mendapatkan sertifikat. Berikut ini adalah beberapa foto kegiatan yang diambil selama pelaksanaan webinar.

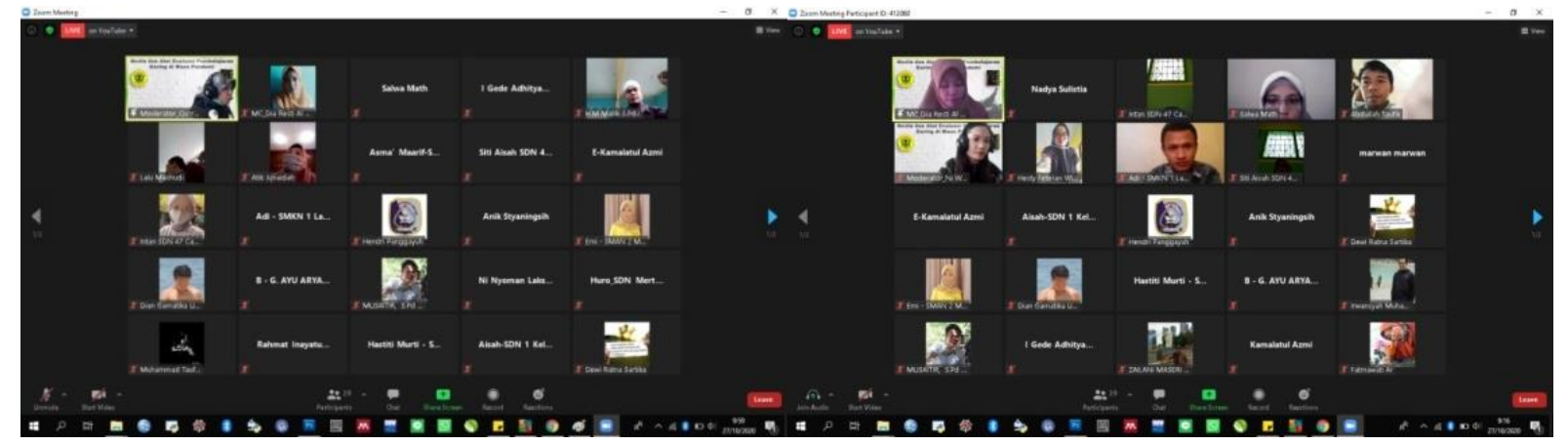

Gambar 1. Hasil screenshoot kegiatan webinar

\section{KESIMPULAN DAN SARAN}

Dari pelaksanaan kegiatan pengabdian kepada masyarakat ini, dapat disimpulkan bahwa tim sudah melaksanakan webinar dengan cukup baik dan lancar. Melalui webinar ini, para guru SD diberikan tutorial menggunakan media pembelajaran digital yang bisa digunakan dalam proses pembelajaran daring selama masa pandemic covid-19, yakni google classroom dan google form. Saran yang dapat diberikan dalam kegiatan pengabdian masyarakat selanjutnya adalah memberikan banyak variasi media pembelajaran yang dapat diakses online maupun offline oleh siswa, dikarenakan oleh masih banyak pula siswa yang tidak memiliki kuota dan gadget yang mendukung pembelajaran daring. 


\section{DAFTAR PUSTAKA}

Allen, M. (2013). Michael Allen's Guide to E-learning. John Wiley \& Sons: Canada.

Khan, L.A. (2015). What is Mathematics-an Overview. International Journal of Mathematics and Computational Science, 1 (3), 98-101. DOI: 10.13140/RG.2.1.3626.8967.

Salwa, Wardhana, I.G.A.W., Aini, Q., Irwansyah, \& Switrayni, N.W. (2020). Pelatihan Membuat dan Menggunakan Media Pembelajaran Daring Dimasa Pandemi. Prosiding PEPADU Vol 22020. http://jurnal.Ippm.unram.ac.id/index.php/prosidingpepadu/article/view/200/pdf

Sepalla, E. (2016). The Happiness Track: How to Apply The Science of Happiness to Accelerate Your Success. HarperOne: New York. 